Article

\title{
Aberrant Promoter Hypermethylation of RASSF Family Members in Merkel Cell Carcinoma
}

Antje M. Richter ${ }^{1}$, Tanja Haag ${ }^{1}$, Sara Walesch ${ }^{1}$, Peter Herrmann-Trost ${ }^{2}$, Wolfgang C. Marsch ${ }^{3}$, Heinz Kutzner ${ }^{4}$, Peter Helmbold ${ }^{5}$ and Reinhard H. Dammann ${ }^{1, *}$

1 Institute for Genetics, University of Giessen, Giessen D-35392, Germany; E-Mails: Antje.Richter@gen.bio.uni-giessen.de (A.M.R.); Tanja.Haag@gen.bio.uni-giessen.de (T.H.); sara.walesch@gen.bio.uni-giessen.de (S.W.) Institute of Pathology, Halle D-06097, Germany; E-Mail: pherrmanntrost@pathologie-halle.de

3 Department of Dermatology, University of Halle, Halle D-06120, Germany; E-Mail: wolfgang.marsch@medizin.uni-halle.de

4 DermPath, Friedrichshafen D-88048, Germany; E-Mail: kutzner@w-4.de

5 Department of Dermatology, University of Heidelberg, Heidelberg D-69120, Germany; E-Mail: Peter.Helmbold@med.uni-heidelberg.de

* Author to whom correspondence should be addressed; E-Mail: Reinhard.Dammann@gen.bio.unigiessen.de; Tel.: +49-641-99-35462; Fax: + 49-641-99-35469.

Received: 11 September 2013; in revised form: 23 October 2013 / Accepted: 8 November 2013 / Published: 18 November 2013

Abstract: Merkel cell carcinoma (MCC) is one of the most aggressive cancers of the skin. RASSFs are a family of tumor suppressors that are frequently inactivated by promoter hypermethylation in various cancers. We studied $\mathrm{CpG}$ island promoter hypermethylation in MCC of RASSF2, RASSF5A, RASSF5C and RASSF10 by combined bisulfite restriction analysis (COBRA) in MCC samples and control tissue. We found RASSF2 to be methylated in three out of 43 (7\%), RASSF5A in 17 out of 39 (44\%, but also 43\% in normal tissue), RASSF5C in two out of $26(8 \%)$ and RASSF10 in 19 out of $84(23 \%)$ of the cancer samples. No correlation between the methylation status of the analyzed RASSFs or between RASSF methylation and MCC characteristics (primary versus metastatic, Merkel cell polyoma virus infection, age, sex) was found. Our results show that RASSF2, RASSF5C and RASSF10 are aberrantly hypermethylated in MCC to a varying degree and this might contribute to Merkel cell carcinogenesis. 
Keywords: merkel cell; tumor suppressor; DNA methylation; epigenetics; RASSF

\begin{abstract}
Abbreviations
MCC: Merkel cell carcinoma; RASSF: Ras-Association Domain Family; TSG: tumor suppressor gene; COBRA: combined bisulfite restriction analysis.
\end{abstract}

\title{
1. Introduction
}

Merkel Cell Carcinoma (MCC) is a rare but aggressive cutaneous malignancy [1] of the elderly with poor prognosis [2]. The malignancy is believed to originate from neuroendocrine cells of the skin. These are found in the dermis of the skin as nerve-associated neuroendocrine cells and in the basal layer of the epidermis of the skin (Merkel cells) [3]. Little is known regarding the molecular mechanism underlying MCC development. It was reported that Merkel Cell Polyomavirus (MCPyV) shows presence in MCCs [4-7] and viral DNA was integrated within the tumor genome in a clonal pattern [5,8]. It was suggested that MCPyV infection is acquired through close contact, possibly involving saliva and/or the skin [9]. Interestingly MCPyV presence was not only found in skin, but also in lung cancer. We have shown RASSF1A promoter methylation and MCPyV presence in small cell lung cancer [10]. In non-small cell lung cancer MCPyV presence was found together with increased BRAF and decreased Bcl2 levels [11]. In MCC however no BRAF(V600E) mutations were found and it was suggested that the classical MAP kinase signal transduction pathway is inactive [12], but mutation of the tumor suppressor p53 in MCC was reported [13]. Additionally we and others have shown promoter hypermethylation of the tumor suppressors p14ARF in 42\% [14] and RASSF1A in 51\% [7] of MCCs. Future studies are needed to elucidate underlying mechanism(s) that drive MCC development and progression.

Tumor suppressor genes (TSG) are commonly inactivated by promoter hypermethylation in cancer. Methylation occurs on the DNA level at 5 ' position of cytosines, when found as dinucleotides with guanine. CpGs are overrepresented in the promoter region of TSG forming so called CpG islands. DNA methylation in CpG islands of TSG leads to epigenetic silencing of the according transcript (as reviewed in $[15,16])$. Well studied epigenetically inactivated TSG are the RASSFs. RASSF abbreviates Ras-association domain family and all ten members are characterized by a Ras-association domain either $C$-terminally (RASSF1-6) or $N$-terminally (RASSF7-10). The functions of the $C$-terminal or classical members range from apoptosis induction, cell cycle inhibition to microtubule stabilization [17].

The focus of our current work was on RASSF2, RASSF5A, RASSF5C and RASSF10, due to the fact that epigenetic inactivation of these tumor suppressors of the RASSF family was already reported in different cancer types. We and others showed promoter hypermethylation of RASSF2 [18-20], RASSF5A [21], RASSF5C [22] and RASSF10 [23-28]. For the most prominent family member RASSF1A we already reported strong promoter hypermethylation in MCC [7], which was in accordance with its status of a very well characterized epigenetically inactivated tumor suppressor [17].

Our aim in the present study was the comparative analysis of RASSF promoter hypermethylation in a set of primary Merkel cell carcinoma and controls. Therefore the promoter regions of RASSF2, 
RASSF5A, RASSF5C and RASSF10 were analyzed by combined bisulfite restriction analysis (COBRA). We show that the degree of promoter hypermethylation in MCC varies between the RASSFs, but is present for different RASSFs at the same time.

\section{Experimental}

\subsection{CpG Island Prediction, PCR Product Size and Digestion Products}

The promoter regions of RASSF2, RASSF5A, RASSF5C and RASSF10 were analyzed by CpG plot [29] to show the existence of a CpG island. Primers for bisulfite treated DNA were designed to bind only fully converted DNA and amplify promoter region of specific RASSFs (listed in Table S1). Promoter region was chosen for $\mathrm{CpG}$ content and presence of according restriction enzymes. COBRA PCR product for RASSF2 is $167 \mathrm{bp}$ with Taq1 sites at position 111. For RASSF5A COBRA PCR product is 334 bp after semi-nested PCR with Taq1 sites at position 94, 234 and 260. COBRA PCR product of RASSF5C is 322 bp after nested PCR with Taq1 sites at position 221 and 284. The RASSF10 COBRA PCR product is $241 \mathrm{bp}$ (with Taq1 sites at 50 and 141) or with alternative primer pair 167 bp (with Taq1 sites at 67). A Summary of COBRA PCR products, CpG islands, primer positions and Taq1 restriction sites is shown in Figure $\mathrm{S} 1$.

\subsection{Merkel Cell Carcinoma and Controls}

We used retrospectively sampled Merkel cell carcinomas from the tumor registries of the University of Heidelberg, the University of Halle (Saale), DermPath Friedrichshafen, and the Institute of Pathology of Halle (Saale). 87 samples of 85 tumors (53 primary MCC, 12 local skin recurrent MCC, 22 MCC skin tumors with uncertain primary/recurrence decision) from 79 patients (76.2 \pm 10.8 years; male/female ratio 0.75$)$ were studied (Table S2). Skin control samples $(n=20)$ were obtained from the skin of surgical surplus areas of routinely-excised and histologically controlled benign nevus cell nevi or benign cysts. A minimum distance of $5 \mathrm{~mm}$ to the lesions as well as exclusion of histological detectable contaminations by cells of the excised lesions or inflammatory infiltrate was guaranteed. MCC were diagnosed histologically by a set of neuroendocrine markers including cytokeratin 20 (CK20) and thyroid transcription factor (TTF)-1 expression. We used corresponding sections of the paraffin-embedded material for hematoxylin and eosin staining, immunostaining and DNA isolation. Merkel cell polyoma virus $(\mathrm{MCPyV})$ infection was investigated in all tumor and control samples as stated previously [7]. Eighty out of 87 (92\%) of the MCC samples and seven out of 20 (35\%) of the control samples showed MCPyV expression (Table S2).

\subsection{DNA Isolation}

Tissue specimens were deparaffinized by xylene and ethanol treatment. DNA was isolated with a QIAamp DNA extraction kit (Qiagen, Hilden, Germany) after a proteinase $\mathrm{K}$ restriction and concentrations of DNA were determined by UV-photospectrometery. 


\subsection{Methylation Analysis by COBRA}

Genomic DNA from MCC or control tissue $(2 \mu \mathrm{g})$ was bisulfite treated $(12 \mu \mathrm{L} 0.1 \quad \mathrm{M}$ hydroquinone, $208 \mu \mathrm{L} 1.9 \mathrm{M}$ sodium metabisulfite and $\mathrm{pH} 5.5$ with $\mathrm{NaOH}$ ) and incubated overnight at $50{ }^{\circ} \mathrm{C}$. Then DNA was purified using MSB Spin PCRapace (STRATEC Molecular, Berlin, Germany), eluted in $50 \mu \mathrm{L} \mathrm{H} \mathrm{H}_{2} \mathrm{O}$ and followed by 10 min incubation with $5 \mu \mathrm{L} 3 \mathrm{M} \mathrm{NaOH}$ at $37{ }^{\circ} \mathrm{C}$. DNA was then precipitated with 100\% ethanol and 7.5 M ammonium acetate and redissolved in $1 \times \mathrm{TE}$ buffer. $200 \mathrm{ng}$ were subsequently used for $25 \mu \mathrm{L}$ PCR reaction with COBRA primers (listed in Table S1). The PCR product was digested with $0.5 \mu \mathrm{L}$ of $\operatorname{Taq} 1$ (Fermentas $\mathrm{GmbH}$, St. Leon-Rot, Germany) $1 \mathrm{~h}$ at $65{ }^{\circ} \mathrm{C}$ and resolved on $2 \%$ TBE gel together with mock digest.

\section{Results}

The RASSF family members RASSF2, RASSF5A, RASSF5C and RASSF10 all contain CpG islands in their promoter region, as analyzed by CpG plot and UCSC Genome browser and as shown in Figure S1. The CpG islands lengths are approximately $1.1 \mathrm{~kb}$ for RASSF2, $1.2 \mathrm{~kb}$ for RASSF5A, $0.5 \mathrm{~kb}$ for RASSF5C and $2.3 \mathrm{~kb}$ for RASSF10. COBRA methylation analysis primers were placed within this region. We used COBRA technique for methylation analysis of the indicated promoters in MCCs and control tissues (Figure S1).

CpG island promoter methylation was analyzed for RASSF2, RASSF5A, RASSF5C and RASSF10 in Merkel cell tumor (Figure 1) and skin control tissue (Figure 2).

Figure 1. COBRA methylation analyses of RASSF2, RASSF5A, RASSF5C and RASSF10 in tumor tissue. Methylation analysis by COBRA for RASSF2, RASSF5A, RASSF5C and RASSF10 was performed and representative results are shown for different tumor samples (numbers are indicated above each gel). DNA was bisulfite treated and COBRA PCR with according primers was performed. Mock (-) and TaqI $(+)$ digested PCR products are resolved in $2 \%$ TBE agarose gel together with 100 bp marker. An in vitro methylated (ivm) DNA was used as positive control. Methylated samples (m) are indicated below and PCR product sizes are shown beside picture.

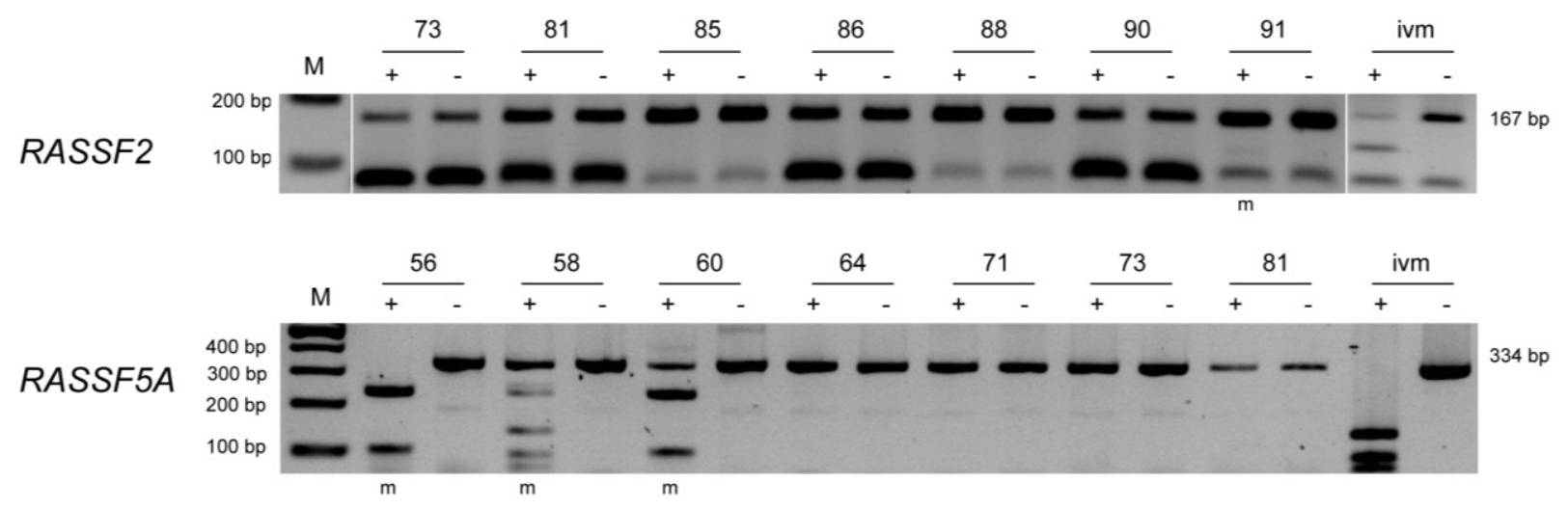


Figure 1. Cont.

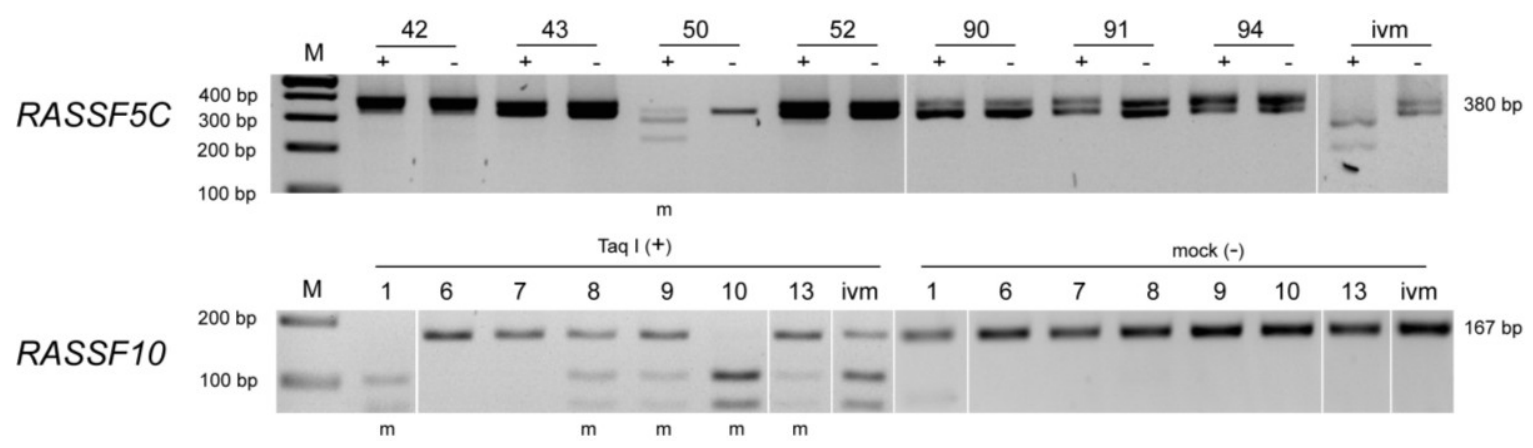

Figure 2. COBRA methylation analyses for RASSF2, RASSF5A, RASSF5C and RASSF10 in control tissue. Methylation analysis by COBRA for RASSF2, RASSF5A, RASSF5C and RASSF10 was performed and representative results are shown for different normal tissues (numbers are indicated above each gel). DNA was bisulfite treated and COBRA PCR with according primers was performed. Mock $(-)$ and TaqI $(+)$ digested PCR products are resolved in 2\% TBE agarose gel together with $100 \mathrm{bp}$ marker. Methylated samples (m) are indicated below and PCR product sizes are shown beside picture.

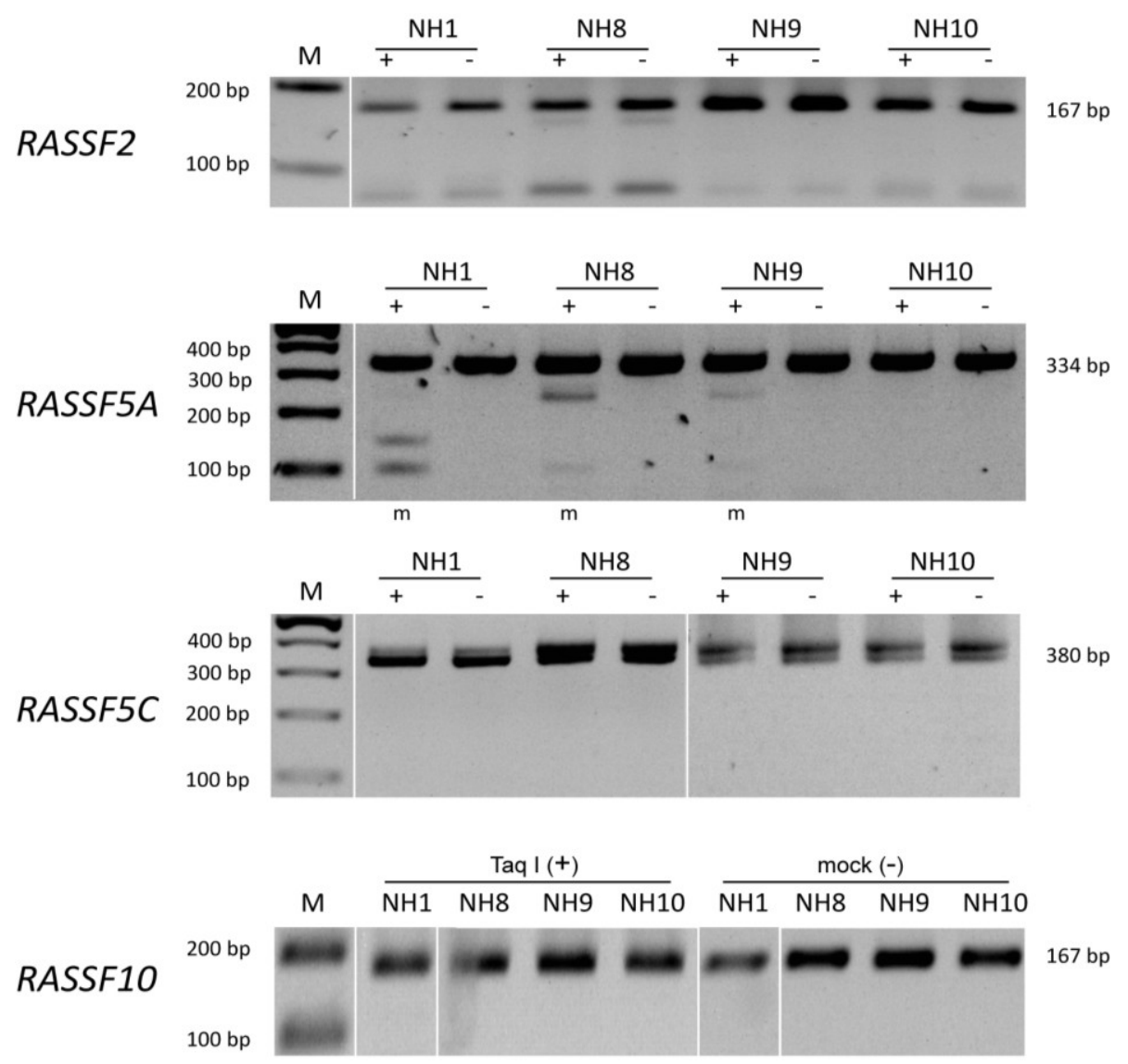

DNA samples were bisulfite treated and COBRA PCR was performed. The PCR product was digested by restriction enzyme and resolved in TBE gel. An in vitro methylated DNA (ivm) was used as positive control. Representative samples are shown for each RASSF promoter analyzed. In case of RASSF2 promoter methylation in MCCs no sample shows digestion products as compared to ivm 
DNA (Figure 1). In control tissue all samples for RASSF2 are unmethylated and therefore undigested (Figure 2). RASSF5A is methylated in samples 56, 58, and 60 (Figure 1), however also control tissue shows some degree of methylation in samples NH1, NH8 and NH9 (Figure 2). RASSF5C is methylated in sample 50 (Figure 1), but not in any of the control samples (Figure 2). Interestingly, RASSF10 promoter analysis shows methylation in samples 1, 8, 9, 10 and 13 (Figure 1), but remains completely unmethylated in control tissue (Figure 2).

Table 1 summarizes the degree of promoter hypermethylation for the analyzed RASSF members in Merkel cell carcinoma tumor samples versus control tissue. For the RASSF2 promoter a total of 43 tumor samples were analyzed and 7\% of these showed hypermethylation. The nine control tissue samples were all unmethylated. The RASSF5A promoter was studied in 39 tumor samples, of which 17 were methylated (44\%). The according control tissue also showed a high degree of RASSF5A promoter methylation (43\%). RASSF5C is methylated to a degree of $8 \%$ in 26 of tumor samples and unmethylated in control tissue. The RASSF10 CpG island promoter methylation was studied in 84 Merkel cell tumor samples of which 19 were methylated. Control tissue (14 samples) was unmethylated at the RASSF10 promoter region.

Table 1. Summary of methylation analysis.

\begin{tabular}{ccc}
\hline Gene & Tumor samples & Control samples \\
\hline$R A S S F 2$ & $7 \%(3 / 43)$ & $0 \%(0 / 9)$ \\
$R A S S F 5 A$ & $44 \%(17 / 39)$ & $43 \%(3 / 7)$ \\
$R A S S F 5 C$ & $8 \%(2 / 26)$ & $0 \%(0 / 11)$ \\
$R A S S F 10$ & $23 \%(19 / 84)$ & $0 \%(0 / 14)$ \\
\hline
\end{tabular}

For details of tumors analyzed regarding MCPyV status and promoter methylation results see Table S2. We found neither a intercorrelation between the promoter methylation statuses nor between the methylation states of each of the investigated promoters and tumor type (primary/metastatic), MCPyV expression, age or sex, respectively (Pearson correlation, $p>0.05$ ).

\section{Discussion}

The aim of this work was to perform a comparative analysis of $\mathrm{CpG}$ island promoter hypermethylation of four Ras-association domain family members in Merkel cell carcinoma. MCC represents one of the most aggressive kinds of skin cancer [1], of which the underlying molecular mechanisms are poorly understood. The RASSF family consists of 10 members [17]. The most prominent family member is RASSF1A, which we already showed to be hypermethylated in MCC [7]. Therefore we studied further RASSF members regarding their promoter methylation state in MCC to test a possible common contribution to Merkel cell cancer formation. The members RASSF2, RASSF5A, RASSF5C and RASSF10 were chosen for this study. The remaining family members were excluded, either because members were previously reported to be only rarely or never epigenetically inactivated in cancer or did not contain a $\mathrm{CpG}$ island promoter at all [17,30].

The RASSF members analyzed in this study have in common a frequent promoter hypermethylation of their CpG island in cancer. The RASSF2 transcript was detected in normal tissue [31], but was shown to be down regulated by hypermethylation of its promoter region in various tumor entities [18-20,31-34]. 
RASSF5 exists in different isoforms as a result of alternative spicing and differential promoter usage. Isoforms $\mathrm{A}$ and $\mathrm{C}$ are transcribed from two separate promoters [35]. Both are expressed in normal tissue, but down-regulated in cancer cell lines [35-38]. We and others found promoter methylation of RASSF5A [19,21] and RASSF5C [22] in tumors. RASSF10 was shown to be hypermethylated at its $\mathrm{CpG}$ island promoter region in various tumor types [23-28] for instance malignant melanoma [25].

The RASSF members chosen for analysis were shown to harbor different functional properties. The mouse model suggests a role of RASSF2 in bone development [39], but also tumor suppressive properties were reported [20,30]. It was demonstrated that RASSF5A has growth suppressive activities [40] and RASSF5C was shown to play a role in lymphoid organs in the mouse system [41]. RASSF10 functions as a tumor suppressor [24,26,42] and additionally we demonstrated a possible role in cell differentiation [24].

In our study we showed that the RASSF2 promoter region was hypermethylated in $7 \%$ of cancer samples, but unmethylated in control tissue. With a total of 43 analyzed tumor samples RASSF2 seems to be hypermethylated in only a small subset of samples. RASSF5A was found to be frequently hypermethylated in Merkel cell carcinoma (44\%), but also in control tissue (43\%). Therefore promoter hypermethylation of RASSF5A seems not to be restricted to MCC. However, previous studies showed that RASSF5A can be epigenetically inactivated by promoter hypermethylation in other cancer types [21]. The RASSF5C promoter showed hypermethylation to a degree of $8 \%$ in Merkel cell carcinoma, but remained unmethylated in control tissue. Similar to RASSF2, only a small number of tumor samples harbor a RASSF5C promoter hypermethylation. The contribution of RASSF2 and RASSF5C promoter hypermethylation to MCC development and progression remains to be addressed. Most notable is the RASSF10 promoter methylation status. We detected 19 out of 84 primary MCC samples to be hypermethylated at the RASSF10 promoter in comparison to none out of 14 investigated control samples. We earlier reported that RASSF1A methylation was a frequent event and reached $51 \%$ in MCC [7], and in this study we show that also the RASSF10 promoter is frequently hypermethylated in MCC (23\%). It is interesting that two members of the tumor suppressor RASSF family are hypermethylated in MCC. Though no correlation between methylation of these two RASSF was found in MCC, possibly due to the limited number of samples, it will be interesting to clarify if hypermethylation of both promoters drives MCC progression. It could be suggested that RASSF1A as a member of the $C$-terminal and RASSF10 as a member of the $N$-terminal family contribute to carcinogenesis through independent mechanisms.

To date only limited functional data exist for RASSF10. However it was shown that the RASSF10 promoter was hypermethylated in cancers. e.g., malignant melanoma of the skin [25]. The current study adds Merkel cell carcinoma to the cancer types showing RASSF10 promoter methylation. Future studies should concentrate to confirm RASSF10 down regulation by promoter hypermethylation in MCC, as epigenetic inactivation of RASSF10 was earlier reported in different cancer cell lines and primary tumors $[24,26,27,42,43]$.

\section{Conclusions}

The present study is the first comparative analysis of RASSF promoter methylation in Merkel cell carcinoma. In summary we were able to show different RASSFs like RASSF2, RASSF5C and 
RASSF10 are tumor specifically methylated at their promoter region in $\mathrm{MCC}$, additional to the earlier reported presence of RASSF1A hypermethylation in MCC [7]. Promoter hypermethylation of tumor suppressors in cancer is a common and early mechanism of their inactivation, which can contributes to cancer progression [44]. Therefore detection of epigenetic changes like DNA methylation markers might prove useful in the early detection of cancer. It will be interesting to extend analysis to a larger set of MCCs to elucidate if correlations between RASSF members and/or clinical parameters are present. Additionally it will be fascinating to study the contribution of several inactive tumor suppressive RASSFs to Merkel cell carcinogenesis.

\section{Acknowledgements}

This work was supported by grants from Deutsche Krebshilfe (German Cancer Aid) 107742 and 107783 and Deutsche Forschungsgemeinschaft (DA-552).

\section{Conflicts of Interest}

The authors declare no conflict of interest.

\section{References}

1. Hodgson, N.C. Merkel cell carcinoma: Changing incidence trends. J. Surg. Oncol. 2005, 89, 1-4.

2. Grabowski, J.; Saltzstein, S.L.; Sadler, G.R.; Tahir, Z.; Blair, S. A comparison of Merkel cell carcinoma and melanoma: Results from the california cancer registry. Clin. Med. Oncol. 2008, 2, 327-333.

3. Spurgeon, M.E.; Lambert, P.F. Merkel cell polyomavirus: A newly discovered human virus with oncogenic potential. Virology 2013, 435, 118-130.

4. Kassem, A.; Schopflin, A.; Diaz, C.; Weyers, W.; Stickeler, E.; Werner, M.; Zur Hausen, A. Frequent detection of Merkel cell polyomavirus in human Merkel cell carcinomas and identification of a unique deletion in the VP1 gene. Cancer Res. 2008, 68, 5009-5013.

5. Feng, H.; Shuda, M.; Chang, Y.; Moore, P.S. Clonal integration of a polyomavirus in human Merkel cell carcinoma. Science 2008, 319, 1096-1100.

6. Becker, J.C.; Houben, R.; Ugurel, S.; Trefzer, U.; Pfohler, C.; Schrama, D. Mc polyomavirus is frequently present in Merkel cell carcinoma of european patients. J. Invest. Dermatol. 2009, 129, 248-250.

7. Helmbold, P.; Lahtz, C.; Enk, A.; Herrmann-Trost, P.; Marsch, W.; Kutzner, H.; Dammann, R.H. Frequent occurrence of RASSF1A promoter hypermethylation and Merkel cell polyomavirus in Merkel cell carcinoma. Mol. Carcinog. 2009, 48, 903-909.

8. Martel-Jantin, C.; Filippone, C.; Cassar, O.; Peter, M.; Tomasic, G.; Vielh, P.; Briere, J.; Petrella, T.; Aubriot-Lorton, M.H.; Mortier, L.; et al. Genetic variability and integration of Merkel cell polyomavirus in Merkel cell carcinoma. Virology 2012, 426, 134-142.

9. Martel-Jantin, C.; Pedergnana, V.; Nicol, J.T.; Leblond, V.; Tregouet, D.A.; Tortevoye, P.; Plancoulaine, S.; Coursaget, P.; Touze, A.; Abel, L.; et al. Merkel cell polyomavirus infection occurs during early childhood and is transmitted between siblings. J. Clin. Virol. 2013, 58, 288-291. 
10. Helmbold, P.; Lahtz, C.; Herpel, E.; Schnabel, P.A.; Dammann, R.H. Frequent hypermethylation of RASSF1A tumour suppressor gene promoter and presence of Merkel cell polyomavirus in small cell lung cancer. Eur. J. Cancer 2009, 45, 2207-2211.

11. Lasithiotaki, I.; Antoniou, K.M.; Derdas, S.P.; Sarchianaki, E.; Symvoulakis, E.K.; Psaraki, A.; Spandidos, D.A.; Stathopoulos, E.N.; Siafakas, N.M.; Sourvinos, G. The presence of Merkel cell polyomavirus is associated with deregulated expression of Braf and Bcl-2 genes in non-small cell lung cancer. Int. J. Cancer 2013, 133, 604-611.

12. Houben, R.; Michel, B.; Vetter-Kauczok, C.S.; Pfohler, C.; Laetsch, B.; Wolter, M.D.; Leonard, J.H.; Trefzer, U.; Ugurel, S.; Schrama, D.; et al. Absence of classical map kinase pathway signalling in Merkel cell carcinoma. J. Invest. Dermatol. 2006, 126, 1135-1142.

13. Van Gele, M.; Kaghad, M.; Leonard, J.H.; van Roy, N.; Naeyaert, J.M.; Geerts, M.L.; van Belle, S.; Cocquyt, V.; Bridge, J.; Sciot, R.; et al. Mutation analysis of P73 and TP53 in Merkel cell carcinoma. Br. J. Cancer 2000, 82, 823-826.

14. Lassacher, A.; Heitzer, E.; Kerl, H.; Wolf, P. p14ARF hypermethylation is common but INK4a-ARF locus or 533 mutations are rare in Merkel cell carcinoma. J. Invest. Dermatol. 2008, 128, 1788-1796.

15. Taberlay, P.C.; Jones, P.A. DNA methylation and cancer. Fortschr. Arzneimittelforsch. 2011, 67, 1-23.

16. Bergman, Y.; Cedar, H. DNA methylation dynamics in health and disease. Nat. Struct. Mol. Biol. 2013, 20, 274-281.

17. Richter, A.M.; Pfeifer, G.P.; Dammann, R.H. The RASSF proteins in cancer; from epigenetic silencing to functional characterization. Biochim. Biophys. Acta 2009, 1796, 114-128.

18. Endoh, M.; Tamura, G.; Honda, T.; Homma, N.; Terashima, M.; Nishizuka, S.; Motoyama, T. RASSF2, a potential tumour suppressor, is silenced by $\mathrm{CpG}$ island hypermethylation in gastric cancer. Br. J. Cancer 2005, 93, 1395-1399.

19. Schagdarsurengin, U.; Richter, A.M.; Hornung, J.; Lange, C.; Steinmann, K.; Dammann, R.H. Frequent epigenetic inactivation of RASSF2 in thyroid cancer and functional consequences. Mol. Cancer 2010, 9, e264.

20. Zhang, Z.; Sun, D.; van do, N.; Tang, A.; Hu, L.; Huang, G. Inactivation of RASSF2A by promoter methylation correlates with lymph node metastasis in nasopharyngeal carcinoma. Int. J. Cancer 2007, 120, 32-38.

21. Hesson, L.; Dallol, A.; Minna, J.D.; Maher, E.R.; Latif, F. NORE1A, a homologue of RASSF1A tumour suppressor gene is inactivated in human cancers. Oncogene 2003, 22, 947-954.

22. Macheiner, D.; Heller, G.; Kappel, S.; Bichler, C.; Stattner, S.; Ziegler, B.; Kandioler, D.; Wrba, F.; Schulte-Hermann, R.; Zochbauer-Muller, S.; et al. NORE1B, a candidate tumor suppressor, is epigenetically silenced in human hepatocellular carcinoma. J. Hepatol. 2006, 45, 81-89.

23. Schagdarsurengin, U.; Richter, A.M.; Wohler, C.; Dammann, R.H. Frequent epigenetic inactivation of RASSF10 in thyroid cancer. Epigenetics 2009, 4, 571-576.

24. Richter, A.M.; Walesch, S.K.; Würl, P.; Taubert, H.; Dammann, R.H. The tumor suppressor RASSF10 is upregulated upon contact inhibition and frequently epigenetically silenced in cancer. Oncogenesis 2012, 1, e18. 
25. Helmbold, P.; Richter, A.M.; Walesch, S.K.; Skorokhod, A.; Marsch, W.C.; Enk, A.; Dammann, R.H. RASSF10 promoter hypermethylation is frequent in malignant melanoma of the skin but uncommon in nevus cell nevi. J. Invest. Dermatol. 2012, 132, 687-694.

26. Hill, V.K.; Underhill-Day, N.; Krex, D.; Robel, K.; Sangan, C.B.; Summersgill, H.R.; Morris, M.; Gentle, D.; Chalmers, A.D.; Maher, E.R.; et al. Epigenetic inactivation of the RASSF10 candidate tumor suppressor gene is a frequent and an early event in gliomagenesis. Oncogene 2010, 30, 978-989.

27. Hesson, L.B.; Dunwell, T.L.; Cooper, W.N.; Catchpoole, D.; Brini, A.T.; Chiaramonte, R.; Griffiths, M.; Chalmers, A.D.; Maher, E.R.; Latif, F. The novel RASSF6 and RASSF10 candidate tumour suppressor genes are frequently epigenetically inactivated in childhood leukaemias. Mol. Cancer 2009, 8, e42.

28. Shinawi, T.; Hill, V.; Dagklis, A.; Baliakas, P.; Stamatopoulos, K.; Agathanggelou, A.; Stankovic, T.; Maher, E.R.; Ghia, P.; Latif, F. KIBRA gene methylation is associated with unfavorable biological prognostic parameters in chronic lymphocytic leukemia. Epigenetics 2012, 7, 211-215.

29. Rice, P.; Longden, I.; Bleasby, A. EMBOSS: The European Molecular Biology Open Software Suite. Available online: http://www.ebi.ac.uk/Tools/seqstats/emboss_cpgplot/ (accessed on 30 April 2013).

30. Underhill-Day, N.; Hill, V.; Latif, F. N-terminal RASSF family: RASSF7-RASSF10. Epigenetics 2011, 6, 284-292.

31. Vos, M.D.; Ellis, C.A.; Elam, C.; Ulku, A.S.; Taylor, B.J.; Clark, G.J. RASSF2 is a novel K-Ras-specific effector and potential tumor suppressor. J. Biol. Chem. 2003, 278, 28045-28051.

32. Hesson, L.B.; Wilson, R.; Morton, D.; Adams, C.; Walker, M.; Maher, E.R.; Latif, F. CpG island promoter hypermethylation of a novel Ras-effector gene RASSF2A is an early event in colon carcinogenesis and correlates inversely with K-ras mutations. Oncogene 2005, 24, 3987-3994.

33. Akino, K.; Toyota, M.; Suzuki, H.; Mita, H.; Sasaki, Y.; Ohe-Toyota, M.; Issa, J.P.; Hinoda, Y.; Imai, K.; Tokino, T. The Ras effector RASSF2 is a novel tumor-suppressor gene in human colorectal cancer. Gastroenterology 2005, 129, 156-169.

34. Park, H.W.; Kang, H.C.; Kim, I.J.; Jang, S.G.; Kim, K.; Yoon, H.J.; Jeong, S.Y.; Park, J.G. Correlation between hypermethylation of the RASSF2A promoter and K-ras/BRAF mutations in microsatellite-stable colorectal cancers. Int. J. Cancer 2007, 120, 7-12.

35. Tommasi, S.; Dammann, R.; Jin, S.G.; Zhang, X.F.; Avruch, J.; Pfeifer, G.P. RASSF3 and NORE1: Identification and cloning of two human homologues of the putative tumor suppressor gene RASSF1. Oncogene 2002, 21, 2713-2720.

36. Chen, J.; Lui, W.O.; Vos, M.D.; Clark, G.J.; Takahashi, M.; Schoumans, J.; Khoo, S.K.; Petillo, D.; Lavery, T.; Sugimura, J.; et al. The $\mathrm{t}(1 ; 3)$ breakpoint-spanning genes LSAMP and NORE1 are involved in clear cell renal cell carcinomas. Cancer Cell 2003, 4, 405-413.

37. Aoyama, Y.; Avruch, J.; Zhang, X.F. Nore1 inhibits tumor cell growth independent of Ras or the MST1/2 kinases. Oncogene 2004, 23, 3426-3433.

38. Vos, M.D.; Martinez, A.; Ellis, C.A.; Vallecorsa, T.; Clark, G.J. The pro-apoptotic Ras effector Nore1 may serve as a Ras-regulated tumor suppressor in the lung. J. Biol. Chem. 2003, 278, 21938-21943. 
39. Song, H.; Kim, H.; Lee, K.; Lee, D.H.; Kim, T.S.; Song, J.Y.; Lee, D.; Choi, D.; Ko, C.Y.; Kim, H.S.; et al. Ablation of RASSF2 induces bone defects and subsequent haematopoietic anomalies in mice. EMBO J. 2012, 31, 1147-1159.

40. Moshnikova, A.; Frye, J.; Shay, J.W.; Minna, J.D.; Khokhlatchev, A.V. The growth and tumor suppressor NORE1A is a cytoskeletal protein that suppresses growth by inhibition of the ERK pathway. J. Biol. Chem. 2006, 281, 8143-8152.

41. Katagiri, K.; Ohnishi, N.; Kabashima, K.; Iyoda, T.; Takeda, N.; Shinkai, Y.; Inaba, K.; Kinashi, T. Crucial functions of the Rap1 effector molecule RAPL in lymphocyte and dendritic cell trafficking. Nat. Immunol. 2004, 5, 1045-1051.

42. Wei, Z.; Chen, X.; Chen, J.; Wang, W.; Xu, X.; Cai, Q. RASSF10 is epigenetically silenced and functions as a tumor suppressor in gastric cancer. Biochem. Biophys. Res. Commun. 2013, 432, 632-637.

43. Dansranjavin, T.; Wagenlehner, F.; Gattenloehner, S.; Steger, K.; Weidner, W.; Dammann, R.; Schagdarsurengin, U. Epigenetic down regulation of RASSF10 and its possible clinical implication in prostate carcinoma. Prostate 2012, doi:10.1002/pros.22510.

44. Dumitrescu, R.G. Epigenetic markers of early tumor development. Methods Mol. Biol. 2012, 863, 3-14.

(C) 2013 by the authors; licensee MDPI, Basel, Switzerland. This article is an open access article distributed under the terms and conditions of the Creative Commons Attribution license (http://creativecommons.org/licenses/by/3.0/). 